\title{
Assembly and Functions of Heterochromatin in the Fission Yeast Genome
}

\author{
O. AYGÜN AND S.I.S. GREWAL \\ Laboratory of Biochemistry and Molecular Biology, National Cancer Institute, Bethesda, Maryland 20892 \\ Correspondence: grewals@mail.nih.gov
}

\begin{abstract}
In eukaryotic genomes, heterochromatin regulates various chromosomal processes including suppression of transcription and illegitimate recombination as well as proper segregation of chromosomes during cell division. Recent studies using the fission yeast Schizosaccharomyces pombe model system have revealed a complex interplay among RNA polymerase II transcription, RNAi machinery, and factors involved in posttranslational modifications of histones that are critical for the assembly and maintenance of heterochromatin. Heterochromatin proteins targeted to specific sites in the genome can spread across extended chromosomal domains and mediate epigenetic genome control by providing a recruitment platform for various factors including chromatin-modifying activities. In this chapter, we discuss mechanisms of heterochromatin assembly in fission yeast and highlight emerging evidence suggesting the involvement of heterochromatin factors in the suppression of noncoding RNAs across the genome.
\end{abstract}

Eukaryotic chromosomes are organized into distinct domains that are critical for proper utilization and maintenance of genetic material. Schizosaccharomyces pombe chromosomes exhibit remarkable similarities to those of higher eukaryotes in terms of their structural organization into specialized domains (Clarke et al. 1986; Allshire 1995; Kniola et al. 2001; Grewal and Jia 2007). Early studies using $S$. pombe revealed that the expression of ectopic reporter genes is subject to epigenetic silencing and position effect variegation when inserted into pericentromeric regions and mating-type loci (Allshire 1995; Grewal and Jia 2007; Klar 2007). These observations led to the discovery of heterochromatin structures that coat extended chromosomal domains (Nakayama et al. 2000; Partridge et al. 2000; Noma et al. 2001; Cam et al. 2005). Initially defined as condensed and cytologically discrete subnuclear structures (Heitz 1928), heterochromatin preferentially targets repetitive DNA elements in the genome to exert a repressive influence on transcription and recombination machineries (Grewal and Jia 2007; Klar 2007). Heterochromatin has also been shown to be critical for centromere and telomere function (Bernard et al. 2001; Nonaka et al. 2002; Kanoh and Ishikawa 2003; Yamagishi et al. 2008), cell fate determination (Jia et al. 2004b), and maintenance of genome stability (Peng and Karpen 2008; Dinant and Luijsterburg 2009; Luijsterburg et al. 2009).

Pervasive transcription across eukaryotic genomes has been linked to widespread occurrence of noncoding RNAs (ncRNAs) (Gingeras 2007; Nicolas et al. 2007; Dutrow et al. 2008; Wilhelm et al. 2008; Zofall et al. 2009). The uncontrolled accumulation of aberrant and noncoding RNAs can have potentially deleterious consequences for the integrity of chromosomes (Aguilera 2002; Li and Manley 2006). Significantly, heterochromatin components have been implicated in the suppression of noncoding RNAs associated with major heterochromatin domains and cer- tain euchromatic regions of the genome (Gullerova and Proudfoot 2008; Zofall et al. 2009).

\section{HISTONE H3 LYSINE 9 METHYLATION: GENOMIC SIGNATURE FOR HETEROCHROMATIN}

Genetic investigations identified mutations in several trans-acting factors involved in heterochromatic silencing of reporter genes inserted at heterochromatic loci and/or processing of mating-type switching in S. pombe (Egel et al. 1984; Klar and Bonaduce 1991; Thon and Klar 1992; Ekwall and Ruusala 1994; Thon et al. 1994; Grewal et al. 1998; Ekwall et al. 1999). The characterization of these factors led to the identification of a core of heterochromatin assembly machinery that is conserved in higher eukaryotes including Drosophila and humans. Among these factors are histone methyltransferase Clr4, HP1 family proteins, and histone deacetylases (HDACs) Clr3 and Clr6 (Grewal and Elgin 2007). In addition, Sir2 protein that deacetylates histone $\mathrm{H} 3$ lysine 9 (H3K9) has been implicated in heterochromatin formation (Shankaranarayana et al. 2003). Clr4 belongs to the mammalian Suv39h family and is the sole fission yeast enzyme that catalyzes methylation of $\mathrm{H} 3 \mathrm{~K} 9$, a chromatin modification often used to define heterochromatic regions of eukaryotic genomes (Nakayama et al. 2001; Noma et al. 2001; Lachner and Jenuwein 2002; Cam et al. 2005). Clr4 forms a multi-subunit protein complex with Rik1 and Cullin 4, which is recruited to sites of heterochromatin assembly (Sadaie et al. 2004; Hong et al. 2005; Horn et al. 2005; Jia et al. 2005). Methylated H3K9 serves as a binding site for the chromodomain proteins such as Chp1, Chp2, and Swi6 (Bannister et al. 2001; Nakayama et al. 2001; Partridge et al. 2002; Sadaie et al. 2004; Cam et al. 2005; Schalch et al. 2009). Genome-wide localization studies have revealed 
that $\mathrm{H} 3 \mathrm{~K} 9 \mathrm{me}$ and chromodomain proteins show similar localization patterns across the genome (Noma et al. 2001; Cam et al. 2005). In particular, these factors are preferentially enriched throughout constitutive heterochromatic domains present at pericentromeric regions, silent matingtype (mat) regions, subtelomeric loci, and ribosomal DNA repeat loci (Cam et al. 2005).

Evidence suggests that the localization of heterochromatin factors is not restricted to constitutively silenced domains. H3K9me and its associated factors have been found associated with several genomic loci including meiotic genes dispersed across the genome (Cam et al. 2005). These sites of heterochromatin formation in otherwise euchromatic domains appear to be akin to facultative heterochromatin in higher eukaryotes. The mechanisms that target heterochromatin to specific sites in the genome and/or mediate the spreading of these repressive structures across extended chromosomal domains have been extensively investigated (see below). Interestingly, Clr4 itself contains a chromodomain, which can recognize H3K9me previously generated by this enzyme and is believed to mediate further recruitment of $\mathrm{Clr} 4$ to heterochromatic regions (Zhang et al. 2008). The self-perpetuating nature of $\mathrm{H} 3 \mathrm{~K} 9 \mathrm{me}$ is critical for the maintenance as well as spreading of heterochromatin (Zhang et al. 2008), further illustrating the key role of this chromatin modification in heterochromatin formation.

\section{RNAI-MEDIATED DEGRADATION OF REPEAT RNAS AND THE SELF-REINFORCING LOOP FOR HETEROCHROMATIN ASSEMBLY}

A key feature of constitutive heterochromatin domains in the $S$. pombe genome is the presence of a specific class of repeat DNA elements, referred to as $d g$ and $d h$ repeats (Clarke et al. 1986; Nakaseko et al. 1986). In addition to copies of these repeat elements present at pericentromeric regions, a $d g / d h$-like element, called $c e n H$, is embedded within a $20-\mathrm{kb}$ heterochromatic domain at the silent mating-type locus (Grewal and Klar 1997). Moreover, a broad distribution of heterochromatin is reported at the subtelomeric loci, which contain a cenH-like element in the coding region of a RecQ helicase gene (Mandell et al. 2005). The importance of these repeat elements in heterochromatin assembly was initially highlighted by results showing that deletion of $c e n H$ causes defects in localization of $\mathrm{H} 3 \mathrm{~K} 9 \mathrm{me}$ and Swi6 that correlate with loss of silencing (Grewal and Klar 1997; Nakayama et al. 2000; Hall et al. 2002). The $d g$ and $d h$ elements are transcribed by RNA polymerase II (RNAPII), but their transcripts are processed by the RNA interference (RNAi) machinery including enzymes Dicer (Dcr1) and Argonaute (Ago1), which degrade these transcripts into short interfering RNAs (siRNAs) (Reinhart and Bartel 2002; Volpe et al. 2002; Grewal and Elgin 2007). These siRNAs are incorporated into a tripartite protein complex referred to as RITS (RNAi-induced transcriptional silencing), which mediates the nuclear RNAi response in fission yeast (Verdel et al. 2004). RITS contains Ago1, Chp1 chromodomain protein, and a protein named Tas3 (Verdel et al.
2004). Deletion of $d c r l$ or components of the RITS causes a dramatic decrease in $\mathrm{H} 3 \mathrm{~K} 9 \mathrm{me}$ and defective silencing of pericentromeric repeat elements (Hall et al. 2002; Volpe et al. 2002; Verdel et al. 2004). Dcr1 is a nuclear protein that specifically localizes to the nuclear periphery, and this localization is critical for its role in heterochromatin assembly (Emmerth et al. 2010). These results have established that RNAi machinery not only mediates degradation of repeat transcripts, but it also contributes to the assembly of heterochromatin structures (Hall et al. 2002; Volpe et al 2002; Noma et al. 2004).

In addition to Dcr1 and Ago1, the fission yeast RNAi machinery includes a third component, RNA-dependent RNA polymerase Rdp1, which is also required for RNAidependent heterochromatin assembly (Hall et al. 2002; Volpe et al. 2002). Rdp1 is a component of RDRC (RNAdirected RNA polymerase complex), which also contains Hrr1 (RNA helicase) and Cid12 (related to poly[A] polymerases) (Motamedi et al. 2004). The RNA-dependent RNA polymerase activity of Rdp1 is required for generation of siRNA, and loss of this activity leads to defective $\mathrm{H} 3 \mathrm{~K} 9$ methylation at pericentromeric repeats (Sugiyama et al. 2005). Rdp1 has been shown to generate secondary siRNA in vivo (Simmer et al. 2010). These analyses suggest that RDRC has an important role in the production of double-stranded RNAs that are processed by Dcr1 to generate siRNAs, which are involved in targeting of heterochromatin (Fig. 1). Recently, it has been suggested that $d g / d h$ transcripts might form hairpin-like secondary structures that can act as double-stranded RNA substrates for Dcr1, therefore generating siRNAs via a mechanism that does not require Rdp1 (Djupedal et al. 2009). Indeed, a small pool of siRNAs can be detected in $r d p 1 \Delta$ cells, leading to the suggestion that these initial siRNAs nucleate heterochromatin without the requirement of RDRC activity (Djupedal et al. 2009).

Genetic and biochemical studies revealed that RNAimediated heterochromatin assembly and degradation of repeat RNA involves a self-reinforcing loop (Noma et al. 2004; Sugiyama et al. 2005). In this mechanism, heterochromatin-bound RNAi machinery generates siRNAs that provide feedback to mediate recruitment of heterochromatin factors. Indeed, RITS and Rdp1 are preferentially enriched at heterochromatic loci, and their distribution patterns closely resemble those of heterochromatin factors (Noma et al. 2004; Verdel et al. 2004; Cam et al. 2005; Sugiyama et al. 2005). RITS localization at centromeres is compromised in the absence of Dcr1 (Verdel et al. 2004; Sugiyama et al. 2005). Furthermore, analysis of RITS recruitment to the silent mating-type region revealed that Dcr1-derived siRNAs are required for targeting RITS to cenH elements (Noma et al. 2004). Defects in localization of RITS in $d c r 1 \Delta$ cells are caused by loss of siRNAs and are not caused by impaired integrity of the complex (Verdel et al. 2004). These observations suggest that siRNAs act as specificity determinants to mediate recruitment of RITS to cognate loci (Cam et al. 2009). This process is believed to involve base-pairing interactions with the nascent transcripts produced by repeat elements (Motamedi et al. 2004; Bühler et al. 2006). The localization 
A

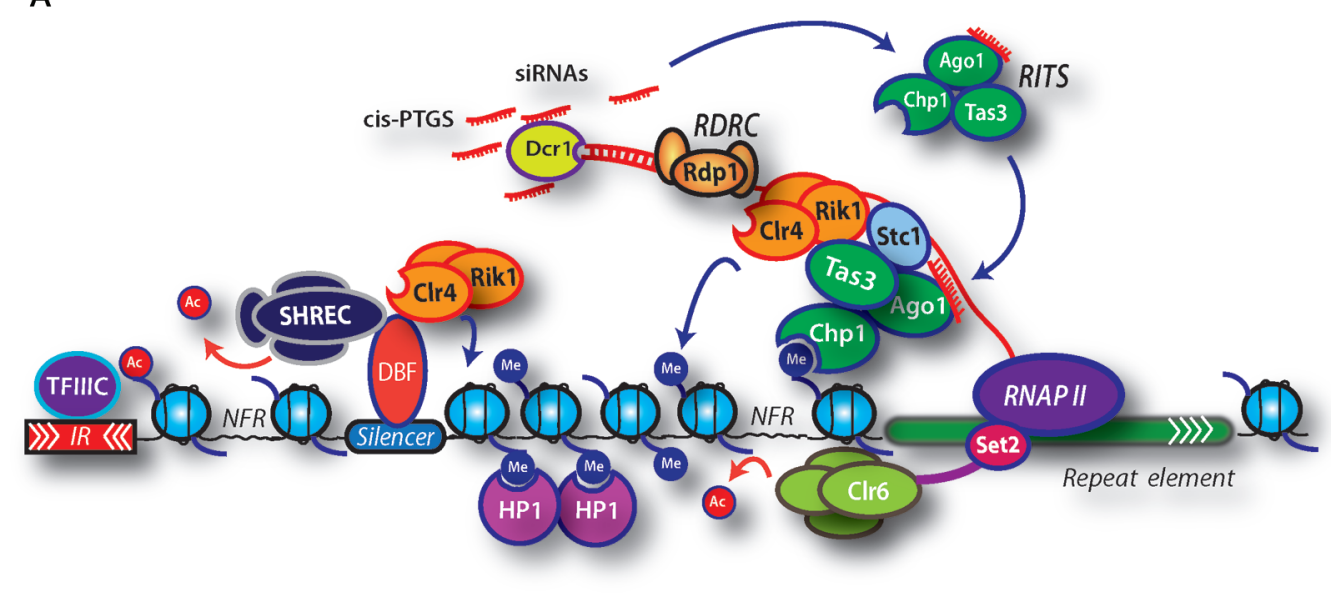

B

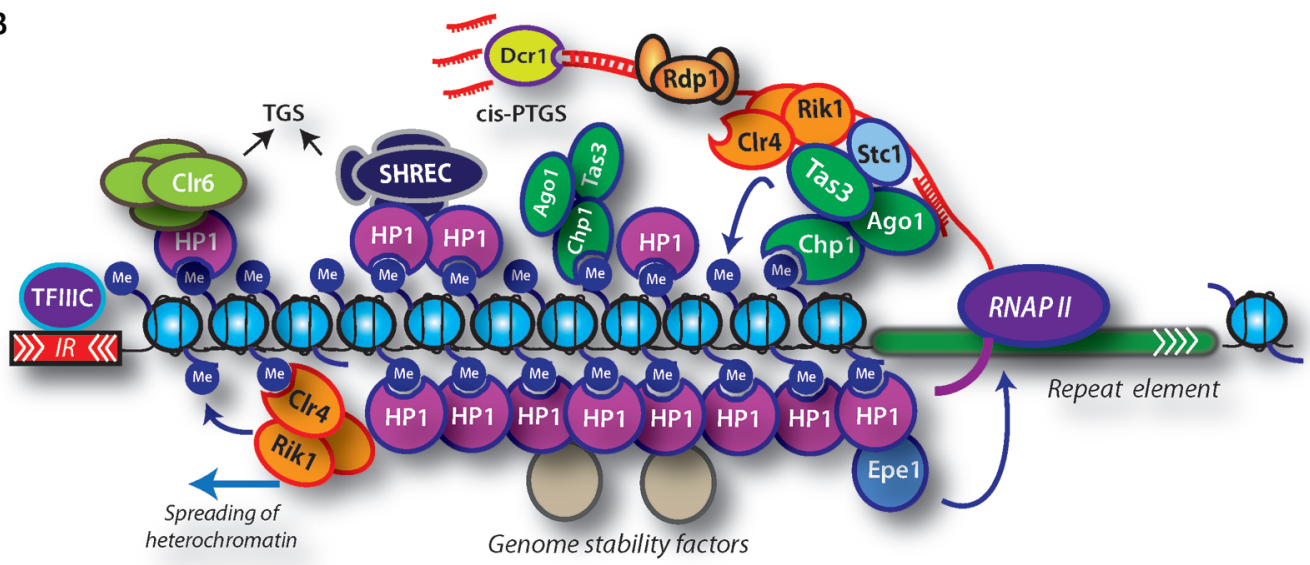

Figure 1. Heterochromatin assembly in S. pombe. (A) Heterochromatin assembly in S. pombe involves RNAi factors, heterochromatin HP1 proteins (Chp2 and Swi6), and histone-modifying factors including methyltransferase Clr4 and HDAC complexes (SHREC and Clr6). Dicer (Dcr1), RNA-induced transcriptional silencing (RITS) complex, and the RNA-dependent RNA polymerase complex (RDRC) process repeat transcripts into siRNAs that are believed to serve as specificity determinants for the loading of heterochromatin. RNAPII transcription of repeats occurs preferentially during S phase of the cell cycle and is functionally coupled to the loading of Clr4 complex subunit Rik1 and the RITS subunit Ago1 as well as methylation of H3K36 by Set2, which is believed to be important for the loading of Clr6 HDAC. The LIM-domain protein Stc1 facilitates the interaction between Clr4 complex and RITS, which stabilizes their binding to chromatin and promotes the processing of repeat RNAs. Recruitment of Clr4 and HDACs likely involves additional transcription-coupled and noncoding-RNA-coupled mechanisms that act independently of RNAi. In addition, DNA-binding factors (DBF) that recognize specific silencer elements within heterochromatin domains target factors required for heterochromatin assembly. Methylation of histone $\mathrm{H} 3$ lysine 9 by Clr4 creates binding sites not only for HP1 proteins but also for the chromodomain of Chp1, a subunit of RITS. The binding of Chp1 to methylated H3K9 (H3K9me) generates a self-reinforcing loop that enables RITS and associated factors to act in cis to process repeat transcripts into siRNAs (cis-PTGS). (B) HP1 proteins bound to H3K9me facilitate the loading of HDACs including SHREC and Clr6. Clr4 is also able to recognize H3K9me via its chromodomain, which is critical for the spreading of heterochromatin. Spreading also requires HP1 proteins and SHREC and involves propagation of heterochromatin-associated modification patterns beyond the initial nucleation sites. The inverted repeat (IR) elements or $t R N A s$, which are bound by transcription factor TFIIIC (Noma et al. 2006), mark the boundaries of heterochromatin domains and prevent inappropriate spreading of heterochromatin outside of the naturally silenced domains. Chp2- and Swi6-mediated recruitment of SHREC and Clr6 activities is also critical for transcriptional gene silencing (TGS). Clr3 HDAC and Mit1 Snf2 ATPase activities of SHREC facilitate proper positioning of nucleosomes to eliminate nucleosome-free regions (NFRs) within heterochromatin and promote TGS by inhibiting RNAPII occupancy. Swi6 can also recruit an antisilencing factor, Epe1, that stimulates transcription of centromeric repeats in the context of heterochromatin. The assembled heterochromatin structure is stably inherited as an epigenetic state and provides a versatile recruitment platform for various factors that have critical roles in genome integrity and organization. 
of Rdp1 to heterochromatic loci also requires Dcr1 and RITS subunits (Sugiyama et al. 2005). Considering that RDRC has been reported to interact with RITS (Motamedi et al. 2004), it is possible that chromatin-bound RITS mediates Rdp1 recruitment to repeat loci (Sugiyama et al. 2005). Significantly, deletion of clr4 almost completely abolishes the localization of RITS and Rdp1 at heterochromatic loci (Noma et al. 2004; Cam et al. 2005; Sugiyama et al. 2005), indicating that stable chromatin association of these factors requires H3K9me and/or Clr4. RITS subunit Chp1 binds H3K9me via its chromodomain (Partridge et al. 2002; Noma et al. 2004; Petrie et al. 2005). Moreover, mutations in the Chp1 chromodomain that severely affect RITS binding to chromatin cause defects in processing of $d g / d h$ transcripts and loss of siRNAs associated with the RITS (Noma et al. 2004; Schalch et al. 2009). These studies revealing a mutual interdependence among H3K9me, $\mathrm{Clr} 4$, and RITS in processing of repeat transcripts into siRNAs and RNAi-dependent heterochromatin assembly have important implications for the assembly and propagation of heterochromatic structures (Fig. 1).

\section{RNAPII TRANSCRIPTION OF CENTROMERIC REPEATS AND ITS LINKS TO HETEROCHROMATIN ASSEMBLY}

A key question that has been focus of intensive research is how RNAi targets Clr4. Although the exact mechanism is still unclear, recent observations have provided important clues (Chen et al. 2008; Zhang et al. 2008; Bayne et al. 2010; Gerace et al. 2010). Paradoxically, RNAPII has an important role in this process, beyond its function in producing the precursors of siRNAs (Chen et al. 2008; Zhang et al. 2008). Mutations in RNAPII subunits and in proteins that are involved in cotranscriptional processes, such as splicing, have been reported to impair heterochromatin formation (Djupedal et al. 2005; Kato et al. 2005; Bayne et al. 2008; Chinen et al. 2009). Evidence suggests that centromeric repeats are transcribed preferentially during S phase of the cell cycle (Chen et al. 2008; Kloc et al. 2008). More importantly, it has been shown that targeting of RITS and Clr4 complex components to centromeric repeats is coupled to RNAPII transcription during S phase (Chen et al. 2008).

During $\mathrm{G}_{2}$ phase, which constitutes a large portion of the $S$. pombe cell cycle, centromeric repeats are assembled in repressive heterochromatin. As cells progress through the cell cycle, phosphorylation of histone $\mathrm{H} 3$ serine 10, a hallmark of mitosis, destabilizes binding of chromodomain proteins to methylated H3K9 (Yamada et al. 2005; Dormann et al. 2006; Chen et al. 2008). Decrease in heterochromatin factors during mitosis is not correlated with elevated levels of RNAPII transcription but is coupled to recruitment of condensin, which is involved in silencing of the centromeric repeats (Chen et al. 2008). However, the $\mathrm{S}$ phase provides a chromatin environment that is amenable to RNAPII transcription of $d g / d h$ repeat elements. Indeed, RNAPII is enriched at repeat elements during a short time window in S phase (Chen et al. 2008) that correlates with the peak of repeat transcripts (Chen et al.
2008; Kloc et al. 2008). Importantly, recruitments of RITS subunit Ago1 and the Rik1 subunit of the Clr4 complex are coupled to RNAPII transcription of repeats (Chen et al. 2008). The preferential loading of Rik1, which contains a potential RNA/DNA-binding domain (Neuwald and Poleksic 2000), occurs specifically at the transcribed portion of repeats and requires Dcr1 (Chen et al. 2008; Zhang et al. 2008). These observations established that Rik1 is the critical component of the Clr4 complex that recognizes the nascent transcripts targeted by RITS to mediate recruitment of Clr4 and RNAi factors (Jia et al. 2005; Chen et al. 2008; Zhang et al. 2008). Supporting this view, RITS coimmunoprecipitates with components of the $\mathrm{Clr} 4 \mathrm{com}$ plex (Zhang et al. 2008; Gerace et al. 2010). Moreover, artificial tethering of Rik1 to a euchromatic reporter transcript induces silencing that is dependent on RNAi machinery (Gerace et al. 2010).

Recently, a novel protein, Stc1, has also been described as a molecular bridge between RITS and the Clr 4 complex (Bayne et al. 2010). Loss of Stc1 abolishes siRNAs derived from $d g / d h$ repeats and affects the establishment of heterochromatin at centromeres and the mat locus (Bayne et al. 2010). Interestingly, Stc1 coimmunoprecipitate with both Ago1 and Clr4 complex subunits (Bayne et al. 2010), leading to the suggestion that Stc1 provides a bridge between RITS bound to nascent transcripts and the Clr4 complex to nucleate heterochromatin (Fig. 1A). In this respect, Stc1 association with centromeric repeats requires Dcr1 and Clr4, and artificial tethering of Stc1 to a reporter gene can bypass the requirement of RNAi for heterochromatin formation (Bayne et al. 2010).

\section{ALTERNATIVE MECHANISMS OF HETEROCHROMATIN ASSEMBLY}

Several lines of evidence suggest the existence of multiple heterochromatin assembly pathways that operate in different chromosomal contexts (Jia et al. 2004a; Kanoh et al. 2005; Yamada et al. 2005). Loss of RNAi machinery does not completely abolish heterochromatin modifications at pericentromeric repeats. Cells carrying deletion of dcrl, agol, or $r d p 1$ maintain measurable levels of H3K9me (Volpe et al. 2002; Sadaie et al. 2004). However, when the null allele of $d c r 1$ is combined with deletion of HDAC $c l r 3$, the resulting double mutants show a dramatic decrease of H3K9me to background levels (Yamada et al. 2005). This observation indicates that $\mathrm{Clr} 3$ is necessary for the establishment or maintenance of H3K9me in the absence of the RNAi machinery (Yamada et al. 2005). Clr3 exists in a multi-subunit silencing complex called SHREC (Snf2/HDAC repressor complex), which can be recruited to heterochromatic loci in the absence of RNAi (Yamada et al. 2005; Sugiyama et al. 2007). It is possible that SHREC directly facilitates targeting of the Clr4 complex to repeat loci. However, an alternative possibility is that SHREC, through its HDAC and Snf2 ATPase activities, creates a chromatin environment that indirectly promotes proper localization of $\mathrm{Clr} 4$ and HP1 proteins and/or prevents turnover of methylated histones. In this regard, it should be noted that loss of Clr3 correlates with a dra- 
matic reduction in $\mathrm{H} 3 \mathrm{~K} 9$ trimethylation and concomitant increase in $\mathrm{H} 3 \mathrm{~K} 9$ monomethylation at heterochromatic loci (Yamada et al. 2005).

Heterochromatin targeting in $S$. pombe also involves sequence-specific DNA-binding factors. Specifically, DNAbinding proteins that bind to specific sites within the silent mating-type locus and telomeres have been implicated in heterochromatin assembly (Jia et al. 2004a; Kanoh et al. 2005). At the mat locus, ATF/CREB family proteins Atf1 and Pcr1 localize to a silencer element (referred to as REIII) and mediate recruitment of heterochromatin factors (Jia et al. 2004a; Kim et al. 2004). Atf1/Pcr1 heterodimer physically interacts with Clr4, Swi6, and HDAC Clr6 involved in heterochromatin assembly (Jia et al. 2004a; Kim et al. 2004). Localization of HDACs also involves CENP$\mathrm{B}$ proteins that bind to a site near cenH elements (Cam et al. 2008). Thus, it appears that multiple recruitment mechanisms are responsible for localization of silencing activities to the mating-type locus. This is further supported by the results illustrating that the loss of RNAi machinery alone is not sufficient to disrupt heterochromatin at this locus, but double mutants carrying deletions of Atf1/Pcr1 and RNAi factors are defective in heterochromatin formation (Jia et al. 2004a; Noma et al. 2004). Similarly, it has been shown that telomere-binding proteins Taz1 (a TRF family protein) and Ccq1 act in a pathway parallel to RNAi machinery to target heterochromatin factors at telomeres in S. pombe (Kanoh et al. 2005; Sugiyama et al. 2007).

These studies illustrate the presence of alternative pathways that operate in conjunction with RNAi to nucleate heterochromatin. The highly stochastic nature of these redundant pathways suggests that RNAi might have evolved to reinforce the heterochromatin assembly and silencing in conjunction with other mechanisms (Fig. 1A). It has recently been suggested that an Argonaute-dependent but Dicer-independent pathway generates small RNAs (referred to as "primal RNAs") that facilitate the initial targeting of heterochromatin at centromeric repeats through their association with Agol (Halic and Moazed 2010). A key prediction of this model is that the loss of Agol but not Dcr1 abolishes H3K9me. However, ago1 1 cells maintain significant levels of $\mathrm{H} 3 \mathrm{~K} 9 \mathrm{me}$ in pericentromeric regions, similar to $d c r 1 \Delta$ cells (Volpe et al. 2002; Sadaie et al. 2004; data not shown). Therefore, although Dicer-independent, Argonaute-dependent small RNAs might exist in $S$. pombe and also as reported in other systems (Ghildiyal and Zamore 2009), further work is required to explore their biological significance.

\section{BEYOND THE REPEAT ELEMENTS: MECHANISMS OF HETEROCHROMATIN SPREADING}

One of the most remarkable characteristics of heterochromatin is its ability to spread beyond the initial nucleation sites across large chromosomal domains (Fig. 1B). The ability of heterochromatin to spread, which is influenced by chromosomal context (Wheeler et al. 2009), is critical to exert epigenetic control over loci located at fur- ther distance. The spreading of heterochromatin across extended chromosomal domains provides a sequence-independent recruiting platform for targeting various effectors to sequences that are otherwise incapable of recruiting those factors by themselves (Grewal and Jia 2007). Heterochromatin spreading is best described by the propagation of specific histone modification patterns beyond the nucleation sites, together with proteins that catalyze and recognize these modifications (Partridge et al. 2000; Noma et al. 2001; Yamada et al. 2005; Zhang et al. 2008). An interesting finding is that long-range spreading of heterochromatin involves the ability of Clr4 both to methylate $\mathrm{H} 3 \mathrm{~K} 9$ and bind to $\mathrm{H} 3 \mathrm{~K} 9 \mathrm{me}$ via its amino-terminal chromodomain (Zhang et al. 2008). Mutations in Clr4 that abolish its binding to $\mathrm{H} 3 \mathrm{~K} 9$ me severely affect spreading of heterochromatin (Zhang et al. 2008). These observations have led to suggestions that $\mathrm{Clr} 4$ bound to methylated $\mathrm{H} 3 \mathrm{~K} 9$ modifies nucleosomes in surrounding regions, which facilitates spreading of heterochromatin. Heterochromatin spreading also requires HP1 proteins (Hall et al. 2002; Noma et al. 2004). Loss of Swi6 function restricts heterochromatin to the nucleation sites at the silent mating-type locus (Hall et al. 2002; Noma et al. 2004). On the other hand, introduction of multiple copies of swi6 enhances the spreading of heterochromatin (Noma et al. 2001). HP1 proteins are known to form dimers via their chromoshadow domains (Brasher et al. 2000; Cowieson et al. 2000), which might contribute to the spreading of heterochromatin by promoting higher-order chromatin organization. However, HP1 proteins also stabilize chromatin association of chromatinmodifying activities (Fischer et al. 2009) such as SHREC (Sugiyama et al. 2007). SHREC promotes proper positioning of nucleosomes (Sugiyama et al. 2007), which is likely to be a critical factor in the spreading and maintenance of heterochromatic structures (Yamada et al. 2005).

The spreading of pericentromeric heterochromatin also requires the catalytic activity of Agol that is involved in slicing of transcripts that are complementary to siRNAs incorporated into RITS (Irvine et al. 2006). Moreover, the Tas 3 subunit of RITS contains an $\alpha$-helical motif that is responsible for oligomerization and therefore mediates spreading of RITS complex in cis (Li et al. 2009). Although these observations implicate RNAi in the spreading of heterochromatin across pericentromeric regions, the RNAi pathway does not have a prominent role in heterochromatin spreading at the mat locus and telomeres (Noma et al. 2004; Kanoh et al. 2005).

\section{NUCLEOSOME POSITIONING AND HETEROCHROMATIC TRANSCRIPTIONAL GENE SILENCING}

In addition to posttranscriptional degradation of RNAs by heterochromatin-associated RNAi machinery, heterochromatin formation also causes transcriptional gene silencing (TGS). Loss of heterochromatin results in elevated levels of RNAPII at the naturally silenced centromeric repeat elements (Yamada et al. 2005; Sugiyama et al. 2007; Chen et al. 2008; Fischer et al. 2009), suggesting that heterochromatin complexes restrict RNAPII occupancy at 
target loci. Genetic and biochemical studies suggest that HP1 proteins Chp2 and Swi6 are critical for the assembly of heterochromatin structure that is inhibitory to transcriptional machinery. The dimerization of HP1 proteins, bound to $\mathrm{H} 3 \mathrm{~K} 9 \mathrm{me}$, may promote chromatin condensation. HP1 proteins serve as a recruiting platform for repressive chromatin-modifying complexes whose activities promote TGS. Specifically, Chp2 and Swi6 mediate the recruitment of SHREC, which contains a class II HDAC Clr3 and Snf2 ATPase Mit1 (Sugiyama et al. 2007; Fischer et al. 2009). Swi6 also associates with another HDAC complex containing class I HDAC Clr6 (Nicolas et al. 2007; Fischer et al. 2009). SHREC and Clr6 are essential for hypoacetylation of histones (Nicolas et al. 2007; Sugiyama et al. 2007), which is a hallmark of heterochromatin domains (Grewal and Jia 2007). Moreover, SHREC activities also influence the dynamics and positioning of nucleosomes (Sugiyama et al. 2007). Mutations in the catalytic site of Clr3 HDAC or Mit1 ATPase influence nucleosome positions that correlate with defective TGS at heterochromatic loci (Sugiyama et al. 2007). These observations suggest that nucleosome positioning by complexes recruited with the help of HP1 proteins is a critical mechanism for heterochromatic TGS. This view is further confirmed by microarray-based mapping of nucleosomes, which revealed that the loss of SHREC or factors involved in its localization, such as Clr4 and HP1 proteins, results in the appearance of nucleosome-free regions at several sites within heterochromatin regions (Garcia et al. 2010). These studies provide a conceptual advance toward understanding the nature of heterochromatic TGS and suggest that positioning of nucleosomes might be a critical determining factor that limits the accessibility of transcriptional machinery to heterochromatic sequences.

Heterochromatic TGS can be modified during cell cycle progression and in response to specific physiological signals. Phosphorylation of Swi6 has been suggested to alter its association with SHREC, thus affecting TGS (Shimada et al. 2009). Paradoxically, Swi6 also recruits a Jmjc-domain-containing antisilencing factor, Epe1, that stimulates RNAPII transcription of centromeric repeats in the context of heterochromatin (Zofall and Grewal 2006; Isaac et al. 2007). Although the antisilencing activity of Epe1 is impaired by mutations affecting its Jmjc domain, the exact function of this conserved protein is still not known. Considering that loss of Epe1 suppresses defective TGS in SHREC mutants, it is possible that Epe1 also modifies nucleosome positioning. These studies suggest that Swi6 recruits opposing activities, the balancing of which might be critical for determining the transcriptional status of target loci (Grewal and Jia 2007). Such a balance between silencing and antisilencing activities could be exploited to facilitate dynamic regulation of heterochromatic loci under different growth conditions.

\section{RNA SURVEILLANCE FUNCTIONS OF HETEROCHROMATIN AND RNAI FACTORS}

As described above, heterochromatin-associated RNAi machinery has been implicated in the processing and elim- ination of repeat-derived transcripts (Volpe et al. 2002; Noma et al. 2004; Cam et al. 2005; Sugiyama et al. 2005; Bühler et al. 2007). Emerging evidence suggests that the influence of RNAi and heterochromatin factors is not restricted to constitutive heterochromatin domains. For instance, RNAi and heterochromatin factors have been shown to localize to several meiotic genes (Cam et al. 2005), the expression of which is regulated by posttranscriptional silencing mechanisms (Harigaya et al. 2006). A surprising finding is that components of the Clr4 complex and RNAi have an important role in suppressing antisense transcripts at euchromatic genes (Gullerova and Proudfoot 2008; Zofall et al. 2009). This is most notable at convergent genes that generate read-through transcripts likely owing to defects in transcription termination. The Clr4 complex subunit Rik1, which resembles cleavage and polyadenylation specificity factors (Neuwald and Poleksic 2000), has been found to localize to euchromatic loci, albeit at low levels (Zofall et al. 2009). Moreover, it has been shown that loss of Clr4, Rik1, or Ago1 causes up-regulation of readthrough antisense transcripts at convergent gene pairs. Heterochromatin assembled at some of these loci might target cohesin, which, in turn, may promote transcription termination (Gullerova and Proudfoot 2008). Interestingly, recent work has uncovered that the Clr4 complex and RNAi factors contribute to the degradation of antisense transcripts (Zofall et al. 2009). To this end, Clr4 and Agol act in a partially redundant manner with a variant histone H2A.Z to promote exosome-mediated degradation of readthrough antisense RNAs (Zofall et al. 2009). Although the exact mechanism(s) underlying this suppression remains to be explored, an interesting possibility is that $\mathrm{Clr} 4$ methylates factors involved in RNA metabolism to facilitate detection and elimination of antisense RNAs. Furthermore, Ago1 protein, which is believed to associate with RNAPII, may cleave RNA, ultimately promoting their destruction by the exonuclease activity of the nuclear exosome. These observations suggest a previously unanticipated role for the Clr4 complex and RNAi machinery in RNA quality control/surveillance to suppress accumulation of potentially deleterious aberrant transcripts at loci outside the confines of classic heterochromatin domains.

\section{CONCLUDING REMARKS}

The last two decades have seen a dramatic change in our understanding of heterochromatin, from a vaguely defined chromosomal entity to a highly versatile and dynamic chromatin structure that has critical roles in various aspects of chromosome biology in eukaryotic genomes. Evidence suggests that heterochromatic structures can be modified in response to environmental and developmental signals, indicating that heterochromatin has evolved into a powerful regulatory mechanism capable of inducing large-scale changes in the genome under different growth conditions. Perhaps one of the most surprising findings is that heterochromatin assembly is mechanistically linked to RNAPII transcription and RNA surveillance machineries and that heterochromatin factors act broadly across large parts of the genome to suppress accumulation of 
aberrant RNAs. These findings have redefined our views about heterochromatin and provided a fertile ground for future studies. In particular, exploring the complex interplay among RNAPII transcription, noncoding RNAs, and heterochromatin factors, as well as investigation of the dynamic nature of heterochromatin structures, promises to provide interesting insights into the mechanisms governing the assembly of specialized chromatin domains in fission yeast, which will facilitate our understanding of the epigenetic regulation of higher eukaryotic genomes.

Note added in proof. Yamane et al. (2011) have found that a histone chaperone complex containing Asf1 and HIRA spreads across silenced domains via its association with Swi6 to enforce transcriptional silencing. They also reported that Asf1 functions in concert with a Clr6 histone deacetylase complex to silence heterochromatic repeats, and it suppresses antisense transcription by promoting histone deacetylation. Importantly, Asf1 and SHREC act in overlapping pathways to promote nucleosome occupancy at heterochromatic regions. These findings suggest that HP1-associated histone chaperones promote nucleosome occupancy to assemble repressive heterochromatin.

\section{ACKNOWLEDGMENTS}

We thank Hugh Cam, Ke Zhang, Sameet Mehta, and Emiko Matsuda for helpful suggestions on the manuscript. Research in the Grewal laboratory is supported by the Intramural Research Program of the National Institutes of Health, National Cancer Institute. O.A is supported by an EMBO Long-Term Postdoctoral Fellowship.

\section{REFERENCES}

Aguilera A. 2002. The connection between transcription and genomic instability. EMBO J 21: 195-201.

Allshire RC. 1995. Elements of chromosome structure and function in fission yeast. Semin Cell Biol 6: 55-64.

Bannister AJ, Zegerman P, Partridge JF, Miska EA, Thomas JO, Allshire RC, Kouzarides T. 2001. Selective recognition of methylated lysine 9 on histone H3 by the HP1 chromo domain. Nature 410: $120-124$

Bayne EH, Portoso M, Kagansky A, Kos-Braun IC, Urano T, Ekwall K, Alves F, Rappsilber J, Allshire RC. 2008. Splicing factors facilitate RNAi-directed silencing in fission yeast. Science 322: 602-606.

Bayne EH, White SA, Kagansky A, Bijos DA, Sanchez-Pulido L, Hoe KL, Kim DU, Park HO, Ponting CP, Rappsilber J, et al. 2010. Stc1: A critical link between RNAi and chromatin modification required for heterochromatin integrity. Cell 140: 666677.

Bernard P, Maure JF, Partridge JF, Genier S, Javerzat JP, Allshire RC. 2001. Requirement of heterochromatin for cohesion at centromeres. Science 294: 2539-2542.

Brasher SV, Smith BO, Fogh RH, Nietlispach D, Thiru A, Nielsen PR, Broadhurst RW, Ball LJ, Murzina NV, Laue ED. 2000. The structure of mouse HP1 suggests a unique mode of single peptide recognition by the shadow chromo domain dimer. $E M B O$ J 19: 1587-1597.

Bühler M, Verdel A, Moazed D. 2006. Tethering RITS to a nascent transcript initiates RNAi- and heterochromatin-dependent gene silencing. Cell 125: 873-886.

Bühler M, Haas W, Gygi SP, Moazed D. 2007. RNAi-dependent and -independent RNA turnover mechanisms contribute to heterochromatic gene silencing. Cell 129: 707-721.
Cam HP, Sugiyama T, Chen ES, Chen X, FitzGerald PC, Grewal SI. 2005. Comprehensive analysis of heterochromatin- and RNAi-mediated epigenetic control of the fission yeast genome. Nat Genet 37: 809-819.

Cam HP, Noma K, Ebina H, Levin HL, Grewal SI. 2008. Host genome surveillance for retrotransposons by transposon-derived proteins. Nature 451: 431-436.

Cam HP, Chen ES, Grewal SI. 2009. Transcriptional scaffolds for heterochromatin assembly. Cell 136: 610-614.

Chen ES, Zhang K, Nicolas E, Cam HP, Zofall M, Grewal SI. 2008. Cell cycle control of centromeric repeat transcription and heterochromatin assembly. Nature 451: 734-737.

Chinen M, Morita M, Fukumura K, Tani T. 2009. Involvement of the spliceosomal U4 small nuclear RNA in heterochromatic gene silencing at fission yeast centromeres. $J$ Biol Chem 285: 5630-5638.

Clarke L, Amstutz H, Fishel B, Carbon J. 1986. Analysis of centromeric DNA in the fission yeast Schizosaccharomyces pombe. Proc Natl Acad Sci 83: 8253-8257.

Cowieson NP, Partridge JF, Allshire RC, McLaughlin PJ. 2000. Dimerisation of a chromo shadow domain and distinctions from the chromodomain as revealed by structural analysis. Curr Biol 10: $517-525$.

Dinant C, Luijsterburg MS. 2009. The emerging role of HP1 in the DNA damage response. Mol Cell Biol 29: 6335-6340.

Djupedal I, Portoso M, Spåhr H, Bonilla C, Gustafsson CM, Allshire RC, Ekwall K. 2005. RNA Pol II subunit Rpb7 promotes centromeric transcription and RNAi-directed chromatin silencing. Genes Dev 19: 2301-2306.

Djupedal I, Kos-Braun IC, Mosher RA, Soderholm N, Simmer F, Hardcastle TJ, Fender A, Heidrich N, Kagansky A, Bayne E, et al. 2009. Analysis of small RNA in fission yeast; centromeric siRNAs are potentially generated through a structured RNA. EMBO J 28: 3832-3844.

Dormann HL, Tseng BS, Allis CD, Funabiki H, Fischle W. 2006. Dynamic regulation of effector protein binding to histone modifications: The biology of HP1 switching. Cell Cycle 5: 28422851.

Dutrow N, Nix DA, Holt D, Milash B, Dalley B, Westbroek E, Parnell TJ, Cairns BR. 2008. Dynamic transcriptome of Schizosaccharomyces pombe shown by RNA-DNA hybrid mapping. Nat Genet 40: 977-986.

Egel R, Beach DH, Klar AJ. 1984. Genes required for initiation and resolution steps of mating-type switching in fission yeast. Proc Natl Acad Sci 81: 3481-3485.

Ekwall K, Ruusala T. 1994. Mutations in rik1, clr2, clr3 and clr4 genes asymmetrically derepress the silent mating-type loci in fission yeast. Genetics 136: 53-64.

Ekwall K, Cranston G, Allshire RC. 1999. Fission yeast mutants that alleviate transcriptional silencing in centromeric flanking repeats and disrupt chromosome segregation. Genetics 153: $1153-1169$

Emmerth S, Schober H, Gaidatzis D, Roloff T, Jacobeit K, Bühler M. 2010. Nuclear retention of fission yeast dicer is a prerequisite for RNAi-mediated heterochromatin assembly. Dev Cell 18: 102-113.

Fischer T, Cui B, Dhakshnamoorthy J, Zhou M, Rubin C, Zofall M, Veenstra TD, Grewal SI. 2009. Diverse roles of HP1 proteins in heterochromatin assembly and functions in fission yeast. Proc Natl Acad Sci 106: 8998-9003.

Garcia JF, Dumesic PA, Hartley PD, El-Samad H, Madhani HD. 2010. Combinatorial, site-specific requirement for heterochromatic silencing factors in the elimination of nucleosome-free regions. Genes Dev 24: 1758-1771.

Gerace EL, Halic M, Moazed D. 2010. The methyltransferase activity of Clr4 $4^{\text {Sur39h }}$ triggers RNAi independently of histone H3K9 methylation. Mol Cell 39: 360-372.

Ghildiyal M, Zamore PD. 2009. Small silencing RNAs: An expanding universe. Nat Rev Genet 10: 94-108.

Gingeras TR. 2007. Origin of phenotypes: Genes and transcripts. Genome Res 17: 682. doi: 10.1101/gr.6525007.

Grewal SI, Elgin SC. 2007. Transcription and RNA interference in the formation of heterochromatin. Nature 447: 399-406. 
Grewal SI, Jia S. 2007. Heterochromatin revisited. Nat Rev Genet 8: $35-46$.

Grewal SI, Klar AJ. 1997. A recombinationally repressed region between mat 2 and mat 3 loci shares homology to centromeric repeats and regulates directionality of mating-type switching in fission yeast. Genetics 146: 1221-1238.

Grewal SI, Bonaduce MJ, Klar AJ. 1998. Histone deacetylase homologs regulate epigenetic inheritance of transcriptional silencing and chromosome segregation in fission yeast. Genetics 150: 563-576.

Gullerova M, Proudfoot NJ. 2008. Cohesin complex promotes transcriptional termination between convergent genes in $S$. pombe. Cell 132: 983-995.

Halic M, Moazed D. 2010. Dicer-independent primal RNAs trigger RNAi and heterochromatin formation. Cell 140: 504-516.

Hall IM, Shankaranarayana GD, Noma K, Ayoub N, Cohen A, Grewal SI. 2002. Establishment and maintenance of a heterochromatin domain. Science 297: 2232-2237.

Harigaya Y, Tanaka H, Yamanaka S, Tanaka K, Watanabe Y, Tsutsumi C, Chikashige Y, Hiraoka Y, Yamashita A, Yamamoto M. 2006. Selective elimination of messenger RNA prevents an incidence of untimely meiosis. Nature 442: 45-50.

Heitz E. 1928. Das heterochromatin der moose. Jahrb Wiss Botanik 69: 762-818.

Hong EJ, Villén J, Gerace EL, Gygi SP, Moazed D. 2005. A cullin E3 ubiquitin ligase complex associates with Rik1 and the Clr4 histone H3-K9 methyltransferase and is required for RNAi-mediated heterochromatin formation. RNA Biol 2: 106-111.

Horn PJ, Bastie JN, Peterson CL. 2005. A Rik1-associated, cullindependent E3 ubiquitin ligase is essential for heterochromatin formation. Genes Dev 19: 1705-1714.

Irvine DV, Zaratiegui M, Tolia NH, Goto DB, Chitwood DH, Vaughn MW, Joshua-Tor L, Martienssen RA. 2006. Argonaute slicing is required for heterochromatic silencing and spreading. Science 313: 1134-1137.

Isaac S, Walfridsson J, Zohar T, Lazar D, Kahan T, Ekwall K, Cohen A. 2007. Interaction of Epe1 with the heterochromatin assembly pathway in Schizosaccharomyces pombe. Genetics 175: 1549-1560.

Jia S, Noma K, Grewal SI. 2004a. RNAi-independent heterochromatin nucleation by the stress-activated ATF/CREB family proteins. Science 304: 1971-1976.

Jia S, Yamada T, Grewal SI. 2004b. Heterochromatin regulates cell type-specific long-range chromatin interactions essential for directed recombination. Cell 119: 469-480.

Jia S, Kobayashi R, Grewal SI. 2005. Ubiquitin ligase component $\mathrm{Cul} 4$ associates with $\mathrm{Clr} 4$ histone methyltransferase to assemble heterochromatin. Nat Cell Biol 7: 1007-1013.

Kanoh J, Ishikawa F. 2003. Composition and conservation of the telomeric complex. Cell Mol Life Sci 60: 2295-2302.

Kanoh J, Sadaie M, Urano T, Ishikawa F. 2005. Telomere binding protein Taz1 establishes Swi6 heterochromatin independently of RNAi at telomeres. Curr Biol 15: 1808-1819.

Kato H, Goto DB, Martienssen RA, Urano T, Furukawa K, Murakami Y. 2005. RNA polymerase II is required for RNAi-dependent heterochromatin assembly. Science 309: 467-469.

Kim HS, Choi ES, Shin JA, Jang YK, Park SD. 2004. Regulation of Swi6/HP1-dependent heterochromatin assembly by cooperation of components of the mitogen-activated protein kinase pathway and a histone deacetylase Clr6. J Biol Chem 279: 42850-42859.

Klar AJ. 2007. Lessons learned from studies of fission yeast mating-type switching and silencing. Annu Rev Genet 41: 213-236.

Klar AJ, Bonaduce MJ. 1991. swi6, a gene required for matingtype switching, prohibits meiotic recombination in the mat2mat3 "cold spot" of fission yeast. Genetics 129: 1033-1042.

Kloc A, Zaratiegui M, Nora E, Martienssen R. 2008. RNA interference guides histone modification during the $\mathrm{S}$ phase of chromosomal replication. Curr Biol 18: 490-495.

Kniola B, O’Toole E, McIntosh JR, Mellone B, Allshire R, Mengarelli S, Hultenby K, Ekwall K. 2001. The domain structure of centromeres is conserved from fission yeast to humans. $\mathrm{Mol}$ Biol Cell 12: 2767-2775.
Lachner M, Jenuwein T. 2002. The many faces of histone lysine methylation. Curr Opin Cell Biol 14: 286-298.

Li X, Manley JL. 2006. Cotranscriptional processes and their influence on genome stability. Genes Dev 20: 1838-1847.

Li H, Motamedi MR, Yip CK, Wang Z, Walz T, Patel DJ, Moazed D. 2009. An $\alpha$ motif at Tas 3 C terminus mediates RITS cis spreading and promotes heterochromatic gene silencing. $\mathrm{Mol}$ Cell 34: 155-167.

Luijsterburg MS, Dinant C, Lans H, Stap J, Wiernasz E, Lagerwerf S, Warmerdam DO, Lindh M, Brink MC, Dobrucki JW, et al. 2009. Heterochromatin protein 1 is recruited to various types of DNA damage. J Cell Biol 185: 577-586.

Mandell JG, Bahler J, Volpe TA, Martienssen RA, Cech TR. 2005. Global expression changes resulting from loss of telomeric DNA in fission yeast. Genome Biol 6: R1. doi: 10.1186/gb2004-6-1-r1.

Motamedi MR, Verdel A, Colmenares SU, Gerber SA, Gygi SP, Moazed D. 2004. Two RNAi complexes, RITS and RDRC, physically interact and localize to noncoding centromeric RNAs. Cell 119: 789-802.

Nakaseko Y, Adachi Y, Funahashi S, Niwa O, Yanagida M. 1986. Chromosome walking shows a highly homologous repetitive sequence present in all the centromere regions of fission yeast. EMBO J 5: 1011-1021.

Nakayama J, Klar AJ, Grewal SI. 2000. A chromodomain protein, Swi6, performs imprinting functions in fission yeast during mitosis and meiosis. Cell 101: 307-317.

Nakayama J, Rice JC, Strahl BD, Allis CD, Grewal SI. 2001. Role of histone $\mathrm{H} 3$ lysine 9 methylation in epigenetic control of heterochromatin assembly. Science 292: 110-113.

Neuwald AF, Poleksic A. 2000. PSI-BLAST searches using hidden markov models of structural repeats: Prediction of an unusual sliding DNA clamp and of $\beta$-propellers in UV-damaged DNAbinding protein. Nucleic Acids Res 28: 3570-3580.

Nicolas E, Yamada T, Cam HP, Fitzgerald PC, Kobayashi R, Grewal SI. 2007. Distinct roles of HDAC complexes in promoter silencing, antisense suppression and DNA damage protection. Nat Struct Mol Biol 14: 372-380.

Noma K, Allis CD, Grewal SI. 2001. Transitions in distinct histone $\mathrm{H} 3$ methylation patterns at the heterochromatin domain boundaries. Science 293: 1150-1155.

Noma K, Sugiyama T, Cam H, Verdel A, Zofall M, Jia S, Moazed D, Grewal SI. 2004. RITS acts in cis to promote RNA interference-mediated transcriptional and post-transcriptional silencing. Nat Genet 36: 1174-1180.

Noma K, Cam HP, Maraia RJ, Grewal SI. 2006. A role for TFIIIC transcription factor complex in genome organization. Cell 125: 859-872.

Nonaka N, Kitajima T, Yokobayashi S, Xiao G, Yamamoto M, Grewal SI, Watanabe Y. 2002. Recruitment of cohesin to heterochromatic regions by Swi6/HP1 in fission yeast. Nat Cell Biol 4: 89-93.

Partridge JF, Borgstrom B, Allshire RC. 2000. Distinct protein interaction domains and protein spreading in a complex centromere. Genes Dev 14: 783-791.

Partridge JF, Scott KS, Bannister AJ, Kouzarides T, Allshire RC. 2002. cis-acting DNA from fission yeast centromeres mediates histone $\mathrm{H} 3$ methylation and recruitment of silencing factors and cohesin to an ectopic site. Curr Biol 12: 1652-1660.

Peng JC, Karpen GH. 2008. Epigenetic regulation of heterochromatic DNA stability. Curr Opin Genet Dev 18: 204-211.

Petrie VJ, Wuitschick JD, Givens CD, Kosinski AM, Partridge JF. 2005. RNA interference (RNAi)-dependent and RNAi-independent association of the Chp1 chromodomain protein with distinct heterochromatic loci in fission yeast. Mol Cell Biol 25: 2331-2346.

Reinhart BJ, Bartel DP. 2002. Small RNAs correspond to centromere heterochromatic repeats. Science 297: 1831. doi: 10. 1126/science. 1077183.

Sadaie M, Iida T, Urano T, Nakayama J. 2004. A chromodomain protein, Chp1, is required for the establishment of heterochromatin in fission yeast. EMBO J 23: 3825-3835.

Schalch T, Job G, Noffsinger VJ, Shanker S, Kuscu C, Joshua-Tor 
L, Partridge JF. 2009. High-affinity binding of Chp1 chromodomain to $\mathrm{K} 9$ methylated histone $\mathrm{H} 3$ is required to establish centromeric heterochromatin. Mol Cell 34: 36-46.

Shankaranarayana GD, Motamedi MR, Moazed D, Grewal SI 2003. Sir2 regulates histone H3 lysine 9 methylation and heterochromatin assembly in fission yeast. Curr Biol 13: 1240-1246.

Shimada A, Dohke K, Sadaie M, Shinmyozu K, Nakayama J, Urano T, Murakami Y. 2009. Phosphorylation of Swi6/HP1 regulates transcriptional gene silencing at heterochromatin. Genes Dev 23: 18-23.

Simmer F, Buscaino A, Kos-Braun IC, Kagansky A, Boukaba A, Urano T, Kerr AR, Allshire RC. 2010. Hairpin RNA induces secondary small interfering RNA synthesis and silencing in trans in fission yeast. EMBO Rep 11: 112-118.

Sugiyama T, Cam H, Verdel A, Moazed D, Grewal SI. 2005. RNAdependent RNA polymerase is an essential component of a selfenforcing loop coupling heterochromatin assembly to siRNA production. Proc Natl Acad Sci 102: 152-157.

Sugiyama T, Cam HP, Sugiyama R, Noma K, Zofall M, Kobayashi R, Grewal SI. 2007. SHREC, an effector complex for heterochromatic transcriptional silencing. Cell 128: 491-504.

Thon G, Klar AJ. 1992. The clrl locus regulates the expression of the cryptic mating-type loci of fission yeast. Genetics 131: 287296.

Thon G, Cohen A, Klar AJ. 1994. Three additional linkage groups that repress transcription and meiotic recombination in the mating-type region of Schizosaccharomyces pombe. Genetics 138: 29-38.

Verdel A, Jia S, Gerber S, Sugiyama T, Gygi S, Grewal SI, Moazed D. 2004. RNAi-mediated targeting of heterochromatin by the RITS complex. Science 303: 672-676.
Volpe TA, Kidner C, Hall IM, Teng G, Grewal SI, Martienssen RA. 2002. Regulation of heterochromatic silencing and histone H3 lysine-9 methylation by RNAi. Science 297: 1833-1837.

Wheeler BS, Blau JA, Willard HF, Scott KC. 2009. The impact of local genome sequence on defining heterochromatin domains. PLoS Genet 5: e1000453. doi: 10.1371/journal.pgen.1000453.

Wilhelm BT, Marguerat S, Watt S, Schubert F, Wood V, Goodhead I, Penkett CJ, Rogers J, Bahler J. 2008. Dynamic repertoire of a eukaryotic transcriptome surveyed at single-nucleotide resolution. Nature 453: 1239-1243.

Yamada T, Fischle W, Sugiyama T, Allis CD, Grewal SI. 2005. The nucleation and maintenance of heterochromatin by a histone deacetylase in fission yeast. Mol Cell 20: 173-185.

Yamagishi Y, Sakuno T, Shimura M, Watanabe Y. 2008. Heterochromatin links to centromeric protection by recruiting shugoshin. Nature 455: 251-255.

Yamane K, Mizuguchi T, Cui B, Zofall M, Noma K, Grewal SI. 2011. Asf1/HIRA facilitate global histone deacetylation and associate with HP1 to promote nucleosome occupancy at heterochromatic loci. Mol Cell 41: 56-66.

Zhang K, Mosch K, Fischle W, Grewal SI. 2008. Roles of the Clr4 methyltransferase complex in nucleation, spreading and maintenance of heterochromatin. Nat Struct Mol Biol 15:381388.

Zofall M, Grewal SI. 2006. Swi6/HP1 recruits a JmjC domain protein to facilitate transcription of heterochromatic repeats. $\mathrm{Mol}$ Cell 22: 681-692.

Zofall M, Fischer T, Zhang K, Zhou M, Cui B, Veenstra TD, Grewal SI. 2009. Histone H2A.Z cooperates with RNAi and heterochromatin factors to suppress antisense RNAs. Nature 461: 419-422. 


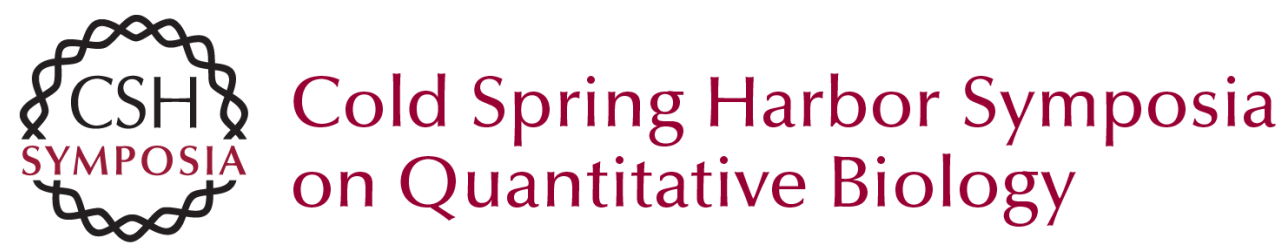

\section{Assembly and Functions of Heterochromatin in the Fission Yeast Genome}

O. Aygün and S.I.S. Grewal

Cold Spring Harb Symp Quant Biol 2010 75: 259-267 originally published online April 18, 2011 Access the most recent version at doi:10.1101/sqb.2010.75.055

References This article cites 93 articles, 29 of which can be accessed free at: http://symposium.cshlp.org/content/75/259.full.html\#ref-list-1

License

Email Alerting

Receive free email alerts when new articles cite this article - sign up in Service the box at the top right corner of the article or click here. 